\title{
TU/e emonownen

\section{Dynamic analysis of a tubular generator for automotive suspension applications}

\section{Citation for published version (APA):}

Kleijer, M., Friedrich, L., Lomonova, E., \& Gysen, B. (2019). Dynamic analysis of a tubular generator for automotive suspension applications. In 2019 12th International Symposium on Linear Drives for Industry Applications, LDIA 2019 [8771025] Institute of Electrical and Electronics Engineers. https://doi.org/10.1109/LDIA.2019.8771025

DOI:

10.1109/LDIA.2019.8771025

Document status and date:

Published: 25/07/2019

\section{Document Version:}

Accepted manuscript including changes made at the peer-review stage

\section{Please check the document version of this publication:}

- A submitted manuscript is the version of the article upon submission and before peer-review. There can be important differences between the submitted version and the official published version of record. People interested in the research are advised to contact the author for the final version of the publication, or visit the $\mathrm{DOI}$ to the publisher's website.

- The final author version and the galley proof are versions of the publication after peer review.

- The final published version features the final layout of the paper including the volume, issue and page numbers.

Link to publication

\section{General rights}

Copyright and moral rights for the publications made accessible in the public portal are retained by the authors and/or other copyright owners and it is a condition of accessing publications that users recognise and abide by the legal requirements associated with these rights.

- Users may download and print one copy of any publication from the public portal for the purpose of private study or research.

- You may not further distribute the material or use it for any profit-making activity or commercial gain

- You may freely distribute the URL identifying the publication in the public portal.

If the publication is distributed under the terms of Article 25fa of the Dutch Copyright Act, indicated by the "Taverne" license above, please follow below link for the End User Agreement:

www.tue.nl/taverne

Take down policy

If you believe that this document breaches copyright please contact us at:

openaccess@tue.nl

providing details and we will investigate your claim. 


\title{
Dynamic Analysis of a Tubular Generator for Automotive Suspension Applications
}

\author{
M. Kleijer*, L.A.J. Friedrich, B.L.J. Gysen, and E.A. Lomonova \\ Department of Electrical Engineering, Eindhoven University of Technology, The Netherlands \\ e-mail: m.kleijer@student.tue.nl
}

\begin{abstract}
In this paper, a slotless three-phase tubular permanent magnet generator applied to vibration energy harvesting in automotive suspensions is considered. A two-dimensional finite element method model of the harvester is created as well as an experimental setup, containing the generator. Signal decomposition utilizing Fourier series is applied to suspension displacement data and the resulting signal components are applied to the model. The individual responses of the model are superposed, from which the corresponding harvested energy is derived. Comparisons are made with measurements on the setup that act as reference to determine the error of the harmonic reconstruction.
\end{abstract}

Index Terms-Vibration energy harvesting, Fourier decomposition analysis

\section{INTRODUCTION}

Due to the increasing electrification of automobiles and their functionalities, active electromechanical suspension solutions have gained popularity [1], [2]. These devices apply active forces on the wheel to counter road irregularities, resulting in improved comfort and safety [3]. An additional benefit from such electromechanical devices is the fact that they are able to recuperate part of the energy that is dissipated in passive systems [4]-[6]. For accurate modeling and design of such a vibration harvester Finite Element Analysis (FEA) has to be conducted, evaluated and intensively iterated to analyze the energy harvesting capabilities of the generator under different road conditions. However, road profile data is chaotic in nature, resulting in the need of fine time-stepping to account for all the frequencies and transient phenomena, which represents a massive computational effort. Hence, analysis by means of harmonic separation and superposition is preferred to lower the time needed to get simulation results. Unfortunately, due to the non-linear material characteristics as well as induced eddy currents in the harvester, this is usually not possible without leading to some inaccuracies [7].

This paper quantifies the error of applying superposition of harmonics to a non-linear problem: the slotless tubular permanent magnet machine, as described in [8], is considered for vibration energy harvesting in automotive suspension applications. In the back-iron of the tubular permanent magnet generator (TPMG) a slit is located to connect the phase wires to the power electronic unit, hence, breaking the axisymmetry and leading to a non-linear problem. Indeed, the eddy current path is blocked and the magnetic loading of the device is influenced. The input suspension displacement data is decomposed in its harmonics using Fourier series.
The individual components are applied to a transient 2D nonlinear finite element method (FEM) model of the TPMG and superposition of the resulting induced emf per harmonic yields meaningful output data, from which harvested energy is calculated. Comparisons are made with measurements on the experimental setup.

\section{METHOD}

The modeling framework to reduce the FEA simulation time for systems with chaotic input profiles consists of the decomposition of the input according to Fourier transforms. Furthermore, reconstruction of simulation outputs is performed by linear superposition, combined with a sideband prediction algorithm to account for the existence of higher harmonic content.

\section{A. Assumptions}

The TPMG is placed in parallel with the suspension system in a quarter car situation, as shown in Fig. 1(a). Here, $M_{u}$, is the unsprung or wheel mass, $M_{s, q}$, represents the sprung or the quarter car body mass, $k_{a}$, and, $d_{a}$, are the spring and damping coefficients of the suspension system, $k_{t}$, is the spring constant of the tire and, $z$, is the suspension displacement due to the road vibrations. The influence of the generator dynamics on the suspension displacement is neglected. Additionally, the power electronics of the harvester are modeled as a resistive circuit, which is illustrated in Fig. 1(b).
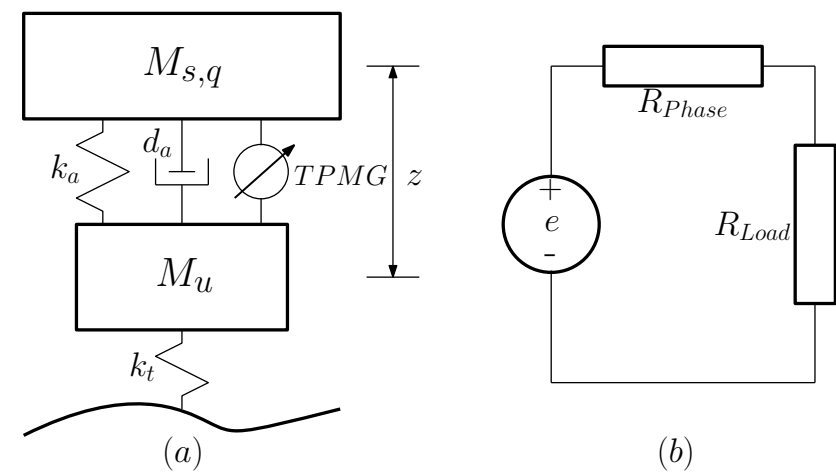

Fig. 1. Schematic overview of (a) the quarter car system with the generator parallel to the suspension system and (b) the considered power electronics circuit. 


\section{B. Signal decomposition}

The suspension displacement data, measured in [3], is used as input for the system. The measurement noise is filtered by limiting the frequency range of the input profile to what corresponds to the operation range of the vehicle. The operation range of the vehicle is defined by the sprung mass resonant frequency

$$
f_{s}=\frac{1}{2 \pi} \sqrt{\frac{k_{a}}{M_{s, q}}},
$$

and the unsprung mass resonant frequency

$$
f_{u}=\frac{1}{2 \pi} \sqrt{\frac{k_{t}}{M_{u}}} .
$$

The mechanical parameters correspond to the values described in [3], [8]. A window of the filtered data is selected in such a way that the first and the last time-step of the displacement profile are equal, indicating a periodic signal, as this guarantees better accuracy of the Fourier transform [9].

The filtered and windowed signal, as shown in Fig. 2(a), is transformed to the frequency domain by applying the Fast Fourier Transform (FFT) algorithm. From the resulting frequency spectrum, given by Fig. 2(b), each frequency component is extracted and transformed back to the time domain using the inverse FFT. As an example, Fig. 3(a) shows the frequency components that belong to the 4 harmonics with the most signal energy in red. Fig. 3(b) provides the resulting harmonics after the inverse FFT.

Each harmonic still has the same sampling as the original signal, but due to the periodicity the harmonics can be reduced to a single period, lowering the amount of time-steps. Additionally, these single period sinusoids can be down-sampled according to the Nyquist-Shannon sampling theorem, which states that the individual harmonics can be represented by at

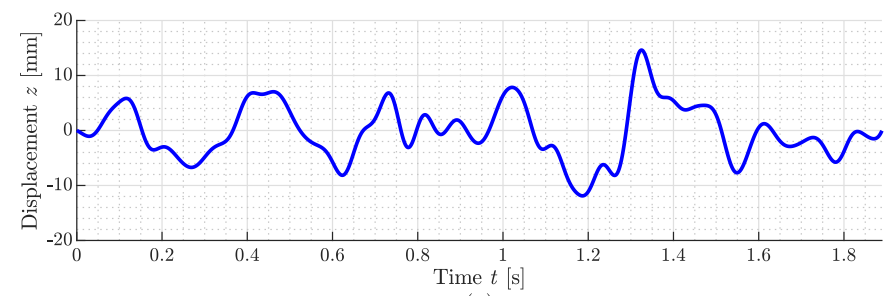

(a)

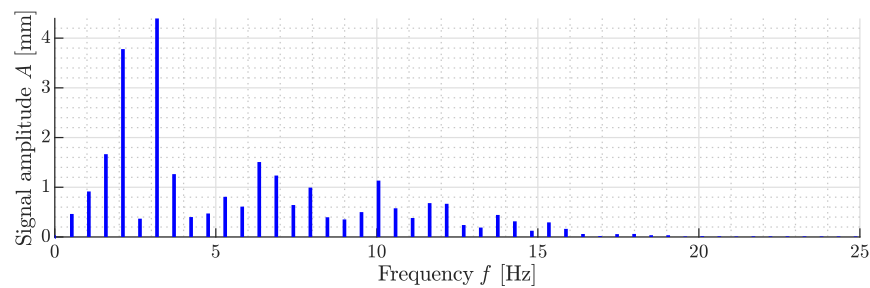

(b)

Fig. 2. (a) Filtered and windowed input displacement signal over time (b) the corresponding frequency spectrum.

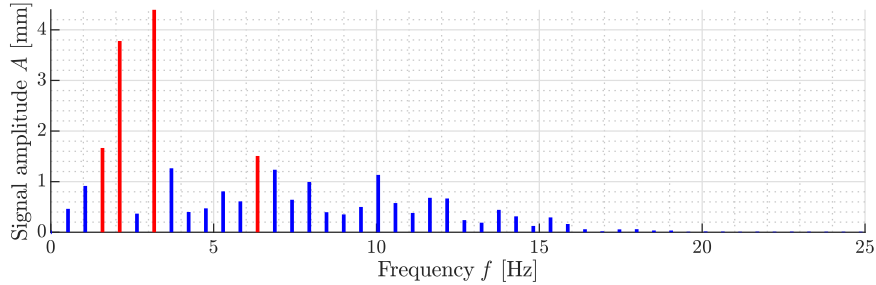

(a)

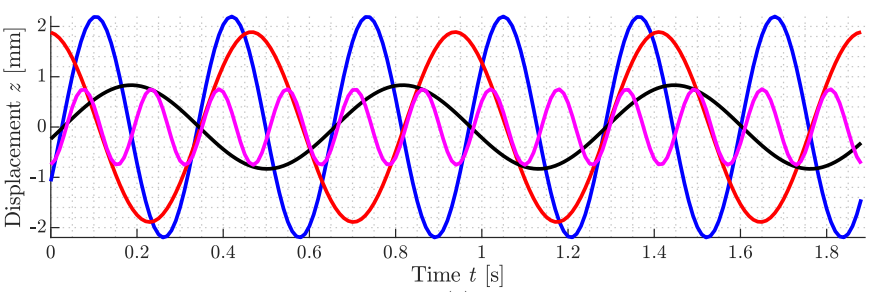

(b)

Fig. 3. (a) Frequency spectrum of the input signal with the frequency components of the first four harmonics indicated in red (b) the resulting harmonic waveforms of the suspension displacement.

least a number of samples that is equal to twice the highest significant frequency component

$$
n_{s}=2 f_{u} .
$$

Fig. 4(a) illustrates the truncation of the harmonics to their single period form, while Fig. 4(b) depicts the down-sampling according to the Nyquist-Shannon theorem. By applying this approach the aforementioned input displacement signal, that consists of roughly 2000 time-steps, can be simulated utilizing 29 harmonics that combined consists of approximately 800 time-steps: a reduction of factor 2.5. A discrepancy

$$
\epsilon=\frac{1}{\left|\hat{u}_{r e f}\right|} \sqrt{\frac{1}{N} \sum_{1}^{N}\left(u_{r e f}-u_{r e c o n}\right)^{2}}
$$

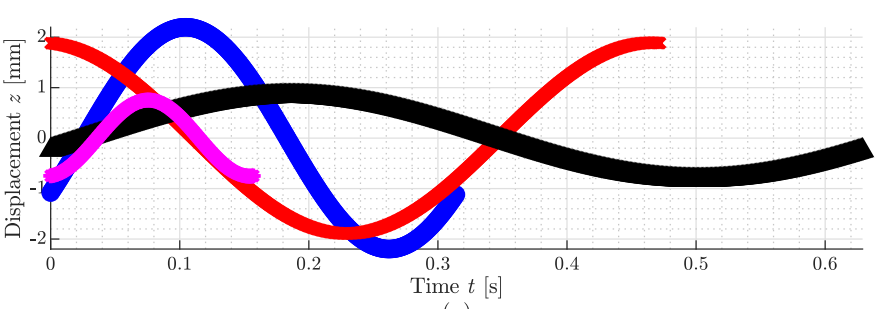

(a)

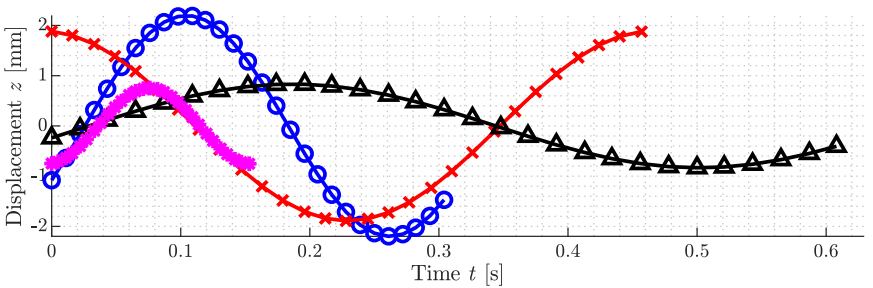

(b)

Fig. 4. (a) Number of time-steps per harmonic shortened to a single period (b) Number of time-steps per truncated harmonic with additional down-sampling. 
of $1.9 \%$ is induced, where, $u_{r e f}$, is the reference signal, $u_{\text {recon }}$, the reconstructed signal utilizing the harmonic decomposition, $\hat{u}_{r e f}$, is the maximum value of the reference signal and, $N$, is the number of time-steps of the signals.

\section{Reconstruction}

Each of the resulting 29 harmonics of the suspension displacement are applied to transient simulations in FEA software [10], which results in 29 induced emf waveforms within the phase windings of the harvester. These $29 \mathrm{emf}$ responses are added together using linear superposition to yield a single emf response that corresponds to the original suspension displacement.

The single phase emf response in a coreless linear machine is given by

$$
e=k_{m} v \cos \left(\frac{\pi z}{\tau_{p}}\right),
$$

where, $k_{m}$, is the motor constant, $v$, the speed that relates to the suspension displacement and, $\tau_{p}$, is the pole pitch of the harvester. Additionally, both, $z$, and, $v$, are single frequency sinusoids for each suspension displacement harmonic and, thus, the frequency spectrum of the resulting emf waveform will contain a fundamental and possibly a third frequency component. However, for the reference suspension displacement profile both, $z$, and, $v$, will be a sum of sinusoids with different frequencies, meaning that higher harmonic content, or sidebands, exist due to the interaction of the suspension displacement and the resulting speed of the mover. This higher harmonic content will not be represented by the simulations of the individual harmonics. Hence, for proper reconstruction this higher harmonic content has to be predicted and added to the linear superposition. As an example, an input suspension displacement that is a sum of two sinusoids is considered. The single phase emf response is rewritten to

$$
e=(a \cos (x)+b \cos (y)) \cos (c \sin (x)+d \sin (y)) .
$$

Here, $c$, and, $d$, are substitutes as in

$$
\begin{aligned}
c & =\frac{\pi A_{1}}{\tau_{p}}, \\
d & =\frac{\pi A_{2}}{\tau_{p}},
\end{aligned}
$$

where, $A_{1}$, and, $A_{2}$, are the amplitudes of the displacement sinusoids. Furthermore, the angular frequencies over time are

$$
\begin{aligned}
& x=2 \pi f_{1} t, \\
& y=2 \pi f_{2} t,
\end{aligned}
$$

where, $f_{1}$, and, $f_{2}$, are the frequencies of the individual components. $a$, and, $b$, are the amplitudes of the cosine as in

$$
\begin{aligned}
& a=k_{m} 2 \pi f_{1} A_{1}, \\
& b=k_{m} 2 \pi f_{2} A_{2} .
\end{aligned}
$$

A Taylor's approximation of degree 4 of a cosine function

$$
\cos (T)=1-\frac{T^{2}}{2 !}+\frac{T^{4}}{4 !}+\mathcal{O}\left(T^{4}\right),
$$

is applied to the second cosine term of (6), where

$$
T=c \sin (x)+d \sin (y) .
$$

The first three resulting Taylor terms are represented by

$$
\begin{aligned}
& T_{1}=(a \cos (x)+b \cos (y)), \\
& T_{2}=-(a \cos (x)+b \cos (y)) \frac{(c \sin (x)+d \sin (y))^{2}}{2 !}, \\
& T_{3}=(a \cos (x)+b \cos (y)) \frac{(c \sin (x)+d \sin (y))^{4}}{4 !} .
\end{aligned}
$$

By rewriting these terms the higher harmonic content due to the speed-displacement interaction is found. As an example the second term, $T_{2}$, is rewritten to

$$
\begin{aligned}
T_{2}= & -\left(\frac{a c^{2}}{8}+\frac{a d^{2}}{4}\right) \cos (x)+\left(\frac{a c^{2}}{8}\right) \cos (3 x) \\
& +\left(\frac{a d^{2}}{8}-\frac{b c d}{4}\right) \cos (x-2 y)+\left(\frac{b c^{2}}{8}-\frac{a c d}{4}\right) \cos (2 x-y) \\
& -\left(\frac{b c^{2}}{4}-\frac{b d^{2}}{8}\right) \cos (y)+\left(\frac{b d^{2}}{8}\right) \cos (3 y) \\
& +\left(\frac{b c^{2}}{8}+\frac{a c d}{4}\right) \cos (2 x+y)+\left(\frac{b c d}{4}+\frac{a d^{2}}{8}\right) \cos (x+2 y) .
\end{aligned}
$$

From (18) it becomes clear that, according to the second Taylor term, the frequency spectrum of the emf response consists of two fundamentals at frequencies, $x$, and, $y$, two third harmonics at frequencies, $3 x$, and, $3 y$, and four sidebands at frequencies, $x-2 y, 2 x-y, 2 x+y$, and, $x+2 y$. By extending this approach to all Taylor terms for the 29 components of the suspension displacement of Fig. 2(a) the prediction of the higher harmonic content is realized and added to the linear superposition.

\section{VALIDATION}

To validate the algorithm for the simulation of chaotic road profile data a transient 2D FEM model of the harvester is produced. Also, an experimental setup that consists of the generator is constructed.

\section{A. FEM model}

Using the dimensions, parameters and materials of the TPMG in [8], a transient 2D FEM model of the harvester is created. A single period of the TPMG is illustrated in Fig. 5. The full device consists of 6 periods and the number of pole pairs is 8.5. Furthermore, the end-effects and the non-linear material characteristics are included in the FEM model. The eddy currents are excluded from the model, as [8] states that the influence of the slit is negligible on the magnetic loading. By applying the same profile to the FEM model as what is used for validation measurements in [8], the accuracy of the model is derived. The induced emf waveforms correspond in shape and are close in magnitude as a discrepancy of $1.6 \%$ is observed, utilizing (4). Hence, the FEM model is validated.

\section{B. Horizontal setup}

Additionally, a horizontal setup, as shown in Fig. 6 is assembled to perform experimental measurements acting as reference, since all the non-linearities are present in the setup. The TPMG is directly coupled to a tubular actuator that is controlled by a driver unit. Suspension displacement profiles 

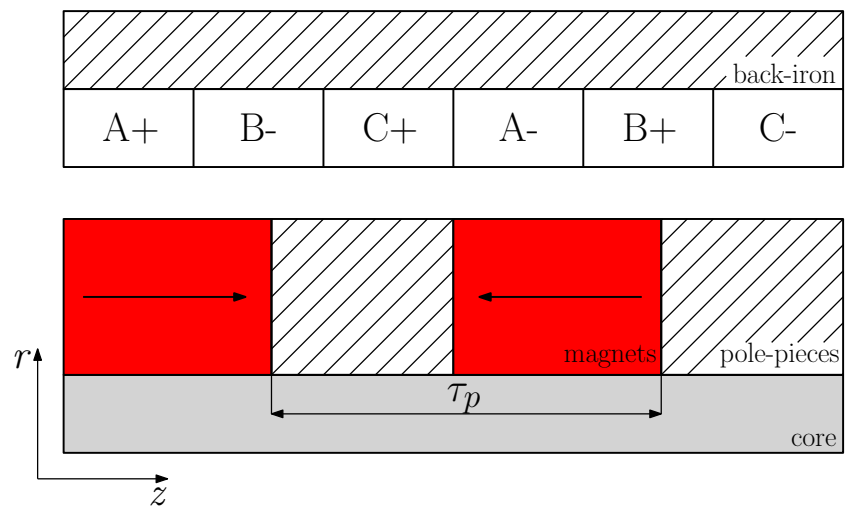

Fig. 5. Schematic of a single period of the TPMG.

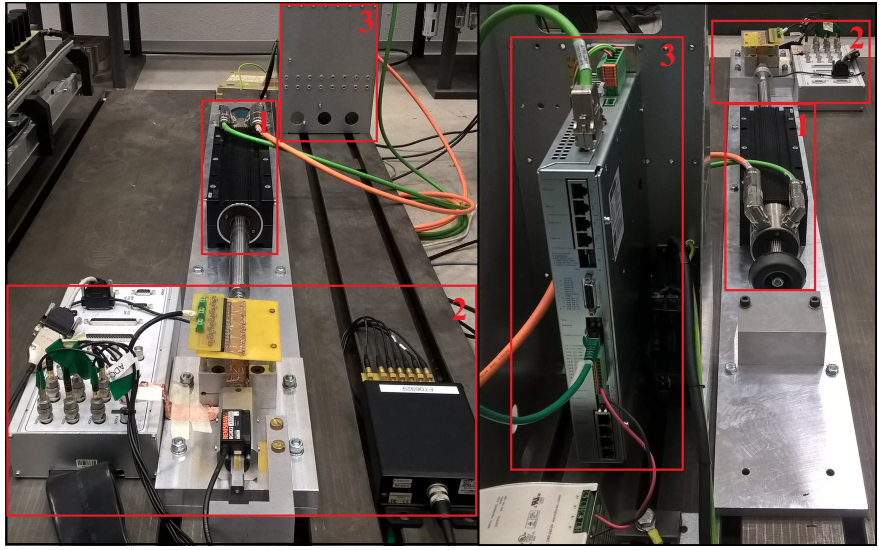

Fig. 6. Front and back view of the setup. 1 indicates the tubular actuator that is used to recreate the suspension displacement waveform, 2 is the TPMG that is used as the harvester together with measurement equipment, 3 is the driver unit that controls the tubular actuator.

can be uploaded unto the driver unit from a PC. The driver ensures the commutation of the actuator to allow for the simulation of the data with a tracking error less than $1 \mathrm{~mm}$. Due to the mechanical connection, the movement will induce emf in the phase windings of the harvester, which is measured using a dSPACE system. Additionally, an optical encoder measures the displacement and the speed of the generator, while a loadcell coupled to the moving part allows for the measurement of the accompanying forces.

Fig. 7 shows the induced emf waveforms of the generator according to the FEM model, as well as measurements by the setup, when the displacement profile of Fig. 2(a) is considered. A deviation of $5 \%$ is observed between the FEM model and the setup.

From the emf waveforms the harvested energy can be derived

$$
E=\int_{0}^{T} \frac{3 e^{2}(t)}{4 R_{\text {phase }}} d t
$$

where, $R_{\text {phase }}$, is the phase resistance of the generator. To maximize the harvested energy, impedance matching is applied to the load resistance of the harvester circuit of Fig. 1(b) [7].

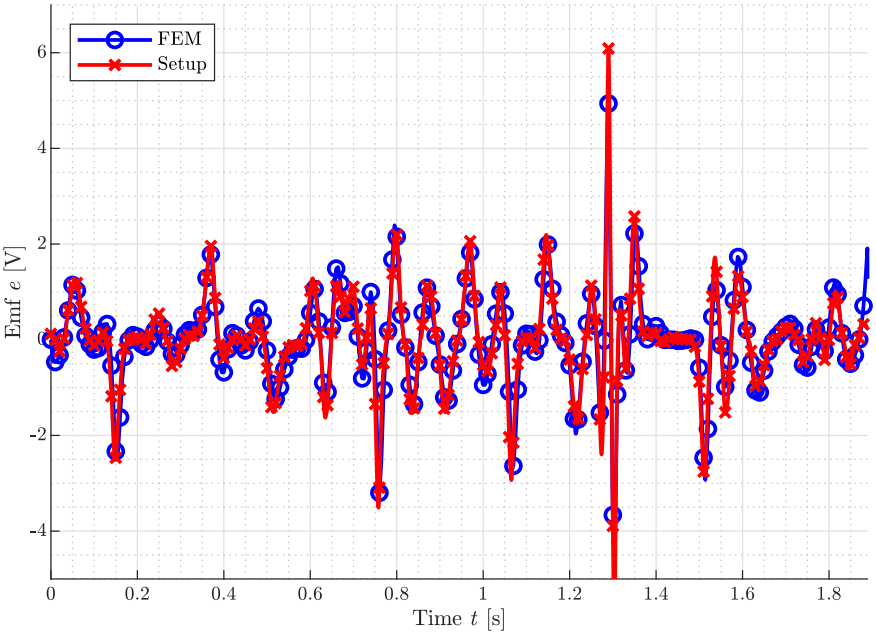

Fig. 7. Comparison of the emf responses of the harvester over time between the FEM model and the setup related to the suspension displacement profile of Fig. 2(a).

The emf waveform and the corresponding harvested energy obtained from the setup act as reference for the decomposition algorithm.

\section{Algorithm accuracy}

With the emf and energy references known from the setup, the accuracy of the harmonic approximation (HA) algorithm can be verified. Table I summarizes the harvested energies obtained by the different methods together with their errors, while Fig. 8(a) compares the reference emf response from the setup with the result of the linear superposition of the 29 individual profiles, utilizing the FEM model. Additionally, Fig. 8(b) adds the sideband prediction. Furthermore, Fig. 9 provides the related frequency spectrums.

From the table and the figures it becomes clear that only the linear superposition of the 29 individual emf responses induces large error. This is caused by the large amount of frequency interaction due to the non-linearity of the reference input profile, which cannot be represented by the individual harmonics. Therefore, when the sideband prediction algorithm is implemented, the results are very promising.

Moreover, by applying the algorithm to a linear case, the reduction of the number of time-steps can be increased to a factor 60 , while a discrepancy of $5.8 \%$ is observed in the emf waveform.

TABLE I

HARVESTED ENERGIES FOR THE REFERENCE PROFILE AND THE TWO ALGORITHM APPROACHES TOGETHER WITH THEIR ERRORS.

\begin{tabular}{|c|c|c|c|}
\hline Signal & Energy [J] & Emf error [\%] & Energy error [\%] \\
\hline Setup reference & 275.8 & - & - \\
\hline HA & 498.6 & 26.7 & 80.8 \\
\hline HA + Sidebands & 289.8 & 7.5 & 5.1 \\
\hline
\end{tabular}




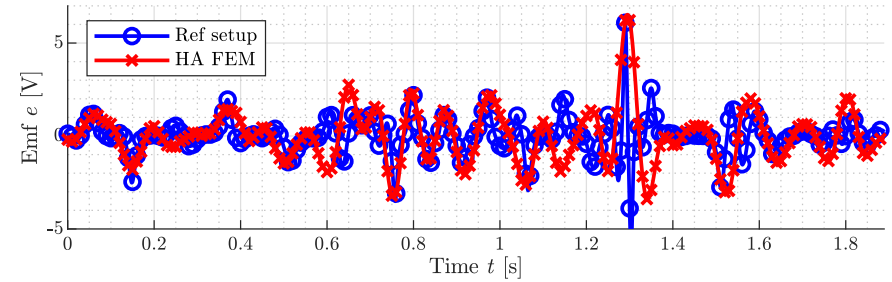

(a)

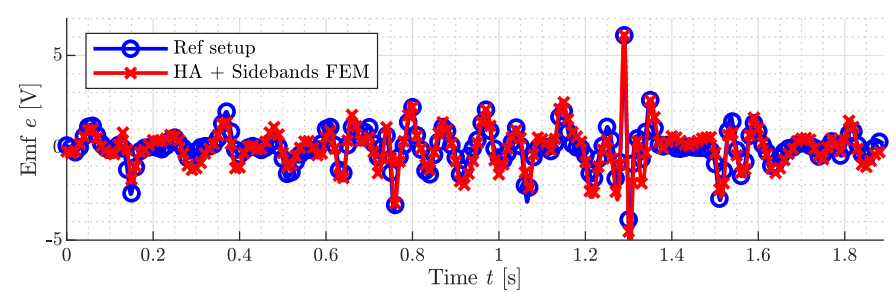

(b)

Fig. 8. Comparison between the reference emf waveform and the linear superposition of the responses of the individual harmonics, (a) without sideband prediction and (b) with sideband prediction.
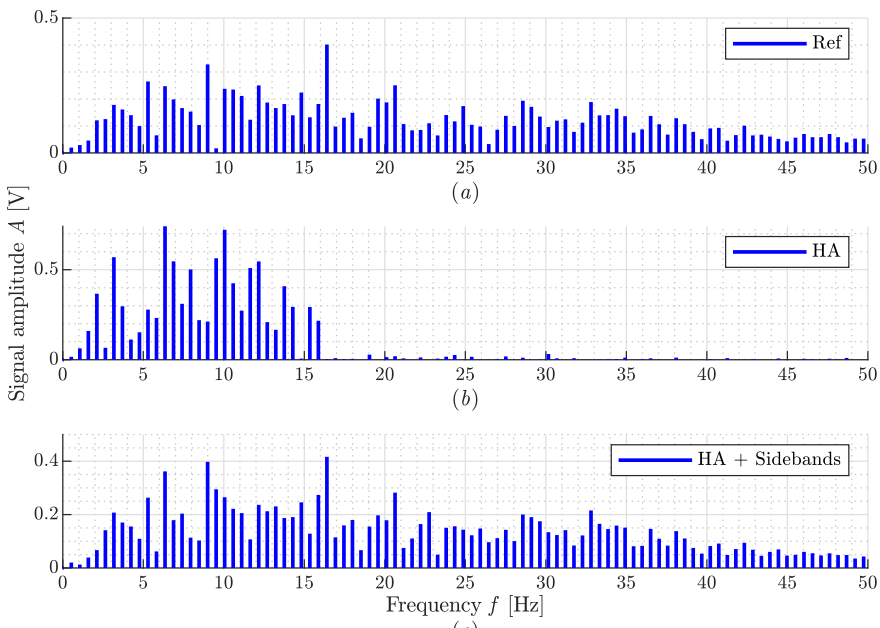

(c)

Fig. 9. Frequency spectrums of (a) the reference profile, (b) the linear superposition of the $29 \mathrm{emf}$ waveforms and (c) the linear superposition with the sideband prediction added.

\section{CONCLUSION}

In this paper, the numerical error induced by using superposition of harmonics to speed up FEA simulations for a non-linear system has been investigated. Harmonic decomposition based on Fourier series has been applied to measured suspension displacement data and the resulting signal components are taken as input for a 2D transient FEM model of a vibration energy harvester. The outputs of the harmonic simulations are reconstructed utilizing linear superposition in combination with a sidebands prediction algorithm. The final results are compared with an experimental setup to quantify the accuracy of the harmonic superposition. A difference of $7.5 \%$ is observed in the induced emf waveforms, together with $5.1 \%$ discrepancy in harvested energies, while simulation time is reduced with a factor of 2.5 utilizing the same transient solver. This can be increased to a factor 60 for linear cases, with a discrepancy of $5.8 \%$ in terms of emf.

\section{REFERENCES}

[1] A. Tonoli, N. Amati, J.G. Detoni, R. Galluzzi, and E. Gasparin, "Modelling and Validation of Electromechanical Shock Absorbers," Vehicle System Dynamics, vol. 51, no. 8, pp. 1186-1199, 2013.

[2] H. Lei, and C. Namuduri, "Electromechanical Regenerative Actuator With Fault-Tolerance Capability for Automotive Chassis Applications," IEEE Transactions on Industry Applications, vol. 49, no. 1, pp. 84-91, 2013.

[3] B.L.J. Gysen, J.J.H. Paulides, J.L.G. Janssen, and E.A. Lomonova, "Active Electromagnetic Suspension System for Improved Vehicle Dynamics," IEEE Transactions on Vehicular Technology, vol. 59, no. 3, pp. $1156-1163,2010$

[4] L. Zuo, and X. Tang, "Large-scale Vibration Energy Harvesting," Journal of intelligent material systems and structures, vol. 24, no. 11, pp. 1405-1430, 2013.

[5] L. Zuo, B. Scully, J. Shestani, and Y. Zhuo, "Design and Characterization of an Electromagnetic Energy Harvester for Vehicle Suspensions," Smart Materials and Structures, vol. 19, 2010.

[6] Z. Li, L. Zuo, J. Kuang, and G. Luhrs, "Energy-Harvesting Shock Absorber with a Mechanical Motion Rectifier," Smart Materials and Structures, vol. 22, no. 2, 2012.

[7] B.A.M. Owens, B.P. Mann, "Linear and Nonlinear Electromagnetic Coupling Models in Vibration-based Energy Harvesting," Journal of Sound and Vibration, vol. 331, no. 4, pp. 922-937, 2012.

[8] K.J. Meessen, J.J.H. Paulides, and E.A. Lomonova, "Modeling and Experimental Verification of a Tubular Actuator for 20-g Acceleration in a Pick-and-Place Application," IEEE Transactions on Industry Applications, vol. 46, no. 5, pp. 1891-1898, 2010.

[9] S. Adamczak, W. Makiea, and K. Stpie, "Investigating Advantages and Disadvantages of the Analysis of a Geometrical Surface Structure with the use of Fourier and Wavelet Transform," Metrology and Measurement Systems, vol. 17, no. 2, pp. 233-244, 2010.

[10] Flux 12.2 Users Guide. 2016. Available online (accessed on 8 April 2019): https://altairhyperworks.com/product/flux. 